\title{
Medication Errors Among Hospitalized Adults in Medical Wards of Nekemte Specialized Hospital, West Ethiopia: A Prospective Observational Study
}

\author{
Mohammed Gebre (D) \\ Nigatu Addisu $\mathbb{( D}^{2}$ \\ Ayantu Getahun ${ }^{3}$ \\ Jenber Workye ${ }^{4}$ \\ Busha Gamachu ${ }^{5}$ \\ Ginenus Fekadu (DD ${ }^{5}$ \\ Tesfa Tekle ${ }^{5}$ \\ Bizuneh Wakuma $\mathbb{D}^{6}$ \\ Getahun Fetensa ${ }^{6}{ }^{6}$ \\ Balisa Mosisa $^{5}$ \\ Getu Bayisa ${ }^{7}$
}

'Department of Pharmacology and Clinical Pharmacy, School of Pharmacy,

College of Health Sciences, Addis Ababa University, Addis Ababa, Ethiopia;

${ }^{2}$ Department of Pharmacy, College of Health and Medical Sciences, Dilla

University, Dilla, Ethiopia; ${ }^{3}$ Department of Public Health, Institute of Health Sciences, Wollega University, Nekemte, Ethiopia; ${ }^{4}$ Department of Pharmacy, College of Health Sciences, Debre Berhan University, Debre Berhan, Ethiopia; ${ }^{5}$ Department of Pharmacy, Institute of Health Sciences, Wollega University, Nekemte, Ethiopia;

${ }^{6}$ Department of Nursing, School of Nursing and Midwifery, Institute of Health Sciences, Wollega University, Nekemte, Ethiopia; ${ }^{7}$ Department of Pharmacy, College of Medicine and Health Sciences, Ambo University, Ambo, Ethiopia

Correspondence: Mohammed Gebre Email mohammed.gebre@aau.edu.et
Purpose: A high prevalence of medication errors in older adults are due to a combination of different factors such as polypharmacy, polymorbidity, enrolment in several diseasemanagement programs, and fragmentation of care that causes medication errors in all age groups. This study aims to assess the incidence and determinants of medication errors among hospitalized adults in medical wards of Nekemte Specialized Hospital (NSH), West Ethiopia.

Patients and Methods: A prospective observational study design was conducted at Nekemte Specialized Hospital among hospitalized adults from October 30, 2018 to January 30, 2019. Data were collected by using checklist-guided observation and review of medication order sheets, medication administration records, and patient charts. To identify the independent predictors of medication errors, logistic regression analysis was used. Statistical significance was considered at a $p$-value $<0.05$.

Results: A total of 351 patients were included in the present study. The mean age of the patients was $40.67+15.78$ years. A total of 813 medication errors were recorded. The most common stage for medication errors was physician ordering 263 (32.4\%). In the multivariable analysis, age $\geq 65$ years (AOR: $2.54,95 \% \mathrm{CI}: 1.12-5.75, p=0.025$ ), hospital stay $\geq 7$ days (AOR: 2.16, 95\%CI: 1.17-3.98, $p=0.014$ ), number of medication taken (AOR: 1.75, 95\%CI: 1.13-2.73, $p=0.013$ ) and presence of comorbidity (AOR: $1.57,95 \% \mathrm{CI}: 1.01-2.46$, $p=0.049$ ) had shown statistical significance in predicting medication errors.

Conclusion: Medication errors are common at Nekemte Specialized Hospital with an incidence of 48.3 per 100 orders, 231.6 per 100 admissions, and 433.4 per 1000 patient days. In particular, adults with older age, increased hospital stay, a greater number of medications, and presence of comorbidities were at greater risk for medication errors.

Keywords: medication error, incidence, determinants, adults, Ethiopia

\section{Introduction}

A medication error (ME) is any preventable event that has the potential to lead to inappropriate medication use or patient harm; it occurs during prescribing, transcribing, dispensing, administering, adherence, or monitoring a drug. ${ }^{1,2}$

The medication use process that comprises prescribing, preparing and administering medications is reliant on a variety of processes anticipated to confirm that patients receive the appropriate treatment. Their safety will be compromised if there is a problem in any phase of either the medication process or an organizational system and this increases the likelihood that a patient will not receive the correct medication. ${ }^{3}$ 
Different studies revealed physician ordering is the most frequently observed stage of integrated medication delivery that is associated with errors, followed by nursing administration, transcription errors, and pharmacy dispensing errors. ${ }^{4,5}$

The most commonly reported errors include: inappropriate medication; incorrect dosage or frequency; wrong route; failure to recognize drug-drug interactions; lack of monitoring; missed/late dose errors with delayed drug administration; and inadequate communication.,

In many clinical settings, adverse drug events (ADEs) and MEs are common and can occur at any point in the process of medication use. About a third to half of ADEs are typically associated with MEs. ${ }^{5}$ Medication errors cause $18.7-56 \%$ of all ADEs and a large number of ADRs with negative patient health outcomes and negative economic impact each year among hospitalized patients. ${ }^{89}$ ADRs refer to any unexpected, unintended, undesired, or excessive response to a medicine. ${ }^{1}$

A high prevalence of MEs in older adults results from the accumulation of factors that contribute to MEs in all age groups; such as polypharmacy, polymorbidity, enrolment in several disease-management programs, and fragmentation of care (the lack of collaboration between health-care providers and/or health-care organizations); and specific geriatric aspects; these include age-related pharmacological changes, lack of specific evidence on the efficacy and safety of medications, underuse of comprehensive assessment, less availability of drug formulations, and inadequate harmonization of recommendations among geriatrics across Europe. ${ }^{10}$ In Ethiopia there are limited studies done on medication errors, this study focuses on assessing medication errors among adults and elderly. Older people are prone for medication errors due to age-related or disease-related physiological and pathological changes that impact on pharmacokinetics and pharmacodynamics, such as impaired renal and hepatic function, altered body composition (eg less muscle mass) and altered homeostatic mechanisms. ${ }^{11}$ This study aims to determine the incidence and determinants of medication errors among hospitalized adults in medical wards of Nekemte Specialized Hospital, West Ethiopia.

\section{Patients and Methods Study Design and Setting}

A prospective observational study design was conducted at Nekemte Specialized Hospital (NSH) among hospitalized adults from October 30, 2018 to January 30, 2019.
The research was conducted at the NSH medical ward which is found in Nekemte town, Oromia Region, Western Ethiopia, $311 \mathrm{~km}$ away from the national capital city, Addis Ababa. NSH is one of the oldest public hospitals in the Oromia region delivering service since 1932. Data of hospital inception is not as important as estimated number of admissions. It provides services in different specialty areas such as surgery, gynecology and obstetrics, pediatrics, internal medicine, psychiatry, chronic disease clinic, and emergency and critical care.

\section{Sample Size Determination and Sampling Technique}

All adult patients admitted to medical wards during the three months of the data collection period and who fulfilled inclusion criteria were studied. A convenient sampling method was used.

\section{Inclusion and Exclusion Criteria}

All adult patients who are admitted to the medical wards of NSH during the study period and taking one or more medications for treatment or prophylaxis and stayed for at least $24 \mathrm{~h}$ in the ward. Patients with incomplete data who were transferred from other wards into medical wards and who were transferred from medical wards to other wards were excluded.

\section{Data Collection Process and Data Quality Assurance}

Data were collected prospectively from chart review by visiting the ward daily and reviewing discharge summary, procedure notes, physician orders, medication administration records, physician progress notes, pertinent laboratory reports, nursing/multidisciplinary progress notes and data about drug exposure was assessed for MEs. Interview of patients and/or parents/family was also made to identify MEs.

Medication errors were identified in accordance with the standard treatment guideline of Ethiopia ${ }^{12}$ and a pharmacotherapy book ${ }^{13}$ was used. In addition, actual occurrences of medication errors were originally reviewed by principal investigators, and severities were evaluated by a panel of four health professionals (two internists and two clinical pharmacists). The cause of medication errors were identified through observation during data collection and reviewing the patient's medical records. 
Data were collected by using a checklist which was adapted from the checklist prepared for California Health Care Foundation ${ }^{14}$ for addressing MEs in hospitals, during hospitalization by visiting the wards daily and examining medical and nursing records. The severity of ME was reported by using the detailed scale published by the National Coordinating Council for Medication Error Reduction and Prevention (NCC MERP). ${ }^{15}$

\section{Data Collection, Analysis and Interpretation}

Data were collected by two pharmacists and two nurses. Before data collection, data collectors were trained by the principal investigator regarding how to go for data collection. Any unclear ideas and terms were explained well for the data collectors. The data collectors have received a written guide that detailed the procedure to be followed. Supervisors had strictly supervised data collectors during data collection. After the data collection process, the principal investigator checked the filled data collection checklist for completeness. Data were entered into a computer using EpiData version 3.1 and was exported to SPSS version 23.0 for analysis. Descriptive statistics were calculated for independent variables after data cleaning, coding and exploration. Frequencies, proportions, mean, and standard deviation were used to describe the study population. The significance and strength of associations were assessed by using an odds ratio with a $95 \%$ confidence interval, along with binary and multiple logistic regression. All factors with a $p$-value $<0.25$ in the bivariate logistic regression analysis were further entered into the multivariate model to control confounding effects. In multiple logistic regression, a $p$-value $<0.05$ was used as statistically significant. Rates of medication errors were reported per 100 orders, 100 admissions, and 1000 patientdays. ${ }^{16}$

\section{Definitions of Terms Wrong Time Error}

Administration of medication outside a predefined time interval from its scheduled administration time (if there is greater than one hour difference between the ordered time and the time the medication is administered). ${ }^{17,18}$

\section{Wrong Dose Error}

Administration to the patient of a dose that is greater than or less than the amount ordered by the prescriber or administration of duplicate doses to the patient, ie, one or more dosage units in addition to those that were ordered. ${ }^{17}$

\section{Transcription Error}

Errors associated with the order transcription and verification process. It includes a variety of omissions, inadvertent cancellations or duplications, and dose transcription errors such as reversing the doses between two drugs or charting a drug that is to be administered every eight hours as every six hours. ${ }^{5}$

\section{Ethical Considerations}

Ethical clearance was obtained from the Institutional Research Ethics Review Committee of Wollega University with approval number WU/IEC:90342/ST149. The patient's written informed consent was obtained after explaining the purpose and procedures of the study. This study was conducted in accordance with the Declaration of Helsinki. Subjects and their responses were kept confidential. For those patients in whom serious medication error detected on the spot intervention was done with appropriate management strategy by discussing with the health-care professionals.

\section{Results}

A total of 351 patients were included in the present study. Patients were followed for a total of 1876 patient-days during the three months of follow-up and a total of 1685 medication orders were given for the study participants. More than half of the patients $(56.1 \%)$ were males. The mean age of the patients was $40.67+15.78$ years. One hundred and sixty-four $(46.7 \%)$ of the patients have stayed in the hospital for four to six days. Three out of five of the participants (60.4\%) had at least one comorbidity. Out of the total study participants, the most commonly reported diseases were infectious disease, 168 (47.9\%) followed by cardiovascular disorders, 85 (24.2\%); neurologic disorders, 66 (18.8\%); gastrointestinal disorders, 55 (15.7\%); and endocrinologic disorders, 47 (13.4\%) (Table 1).

Among a total of 1685 medication orders, the most ordered drugs for the patients during their hospital stay were antimicrobials $(22.2 \%)$, followed by analgesics (15.4\%), gastrointestinal drugs (12.7\%) and cardiovascular drugs (12.2\%) (Table 2).

During three months of follow-up, the study included 351 admissions and 1876 patient-days, during which 1685 medication orders were written. The incidence of 
Table I Characteristics of the Patients Admitted in Nekemte Specialized Hospital $(n=35 \mathrm{I})$

\begin{tabular}{|c|c|c|c|}
\hline Variables & Category & Frequency & Percent (\%) \\
\hline \multirow[t]{2}{*}{ Sex } & Female & 154 & 43.9 \\
\hline & Male & 197 & 56.1 \\
\hline \multirow[t]{3}{*}{ Age } & $18-34$ & 140 & 39.9 \\
\hline & $35-64$ & 178 & 50.7 \\
\hline & $\geq 65$ & 33 & 9.4 \\
\hline \multirow[t]{3}{*}{ Hospital stay } & $\mathrm{I}-3$ & 105 & 29.9 \\
\hline & 4-6 & 164 & 46.7 \\
\hline & $\geq 7$ & 82 & 23.4 \\
\hline \multirow{2}{*}{$\begin{array}{l}\text { Number of } \\
\text { medications }\end{array}$} & $\leq 4$ & 158 & 45.0 \\
\hline & $\leq 5$ & 193 & 55.0 \\
\hline \multirow{2}{*}{$\begin{array}{l}\text { Presence of } \\
\text { comorbidity }\end{array}$} & No & 139 & 39.6 \\
\hline & Yes & 212 & 60.4 \\
\hline \multirow{12}{*}{$\begin{array}{l}\text { Diagnosed } \\
\text { diseases }\end{array}$} & Infectious disease & 168 & 47.9 \\
\hline & $\begin{array}{l}\text { Cardiovascular } \\
\text { disorders }\end{array}$ & 85 & 24.2 \\
\hline & $\begin{array}{l}\text { Gastrointestinal } \\
\text { disorders }\end{array}$ & 55 & 15.7 \\
\hline & Respiratory & 42 & 12.0 \\
\hline & disorders & & \\
\hline & Renal disorders & 32 & 9.1 \\
\hline & $\begin{array}{l}\text { Dermatologic } \\
\text { disorders }\end{array}$ & 10 & 2.8 \\
\hline & $\begin{array}{l}\text { Hematologic } \\
\text { disorders }\end{array}$ & 44 & 12.5 \\
\hline & $\begin{array}{l}\text { Endocrinologic } \\
\text { disorders }\end{array}$ & 47 & 13.4 \\
\hline & $\begin{array}{l}\text { Neurologic } \\
\text { disorders }\end{array}$ & 66 & 18.8 \\
\hline & Malnutrition & 3 & 0.9 \\
\hline & Others & 8 & 2.3 \\
\hline
\end{tabular}

medication errors per 100 orders was 48.3 , per 100 admissions 231.6 and per 1000 patient-days 433.4 .

Among the study participants, 178 (50.7\%) encountered medication errors, and $131(37.3 \%)$ patients had three or more medication errors. Overall, there were 813 medication errors from 1685 medication orders and 1876 patient-days. A total of 813 medication errors were recorded. Among the medication errors, 213 (26.2\%) were wrong drug, $183(22.5 \%)$ were wrong dose, 130 $(16.0 \%)$ were monitoring error and $81(10.0 \%)$ were wrong frequency. The most common stage for medication errors was physician ordering 263 (32.4\%), followed by nurse administering 167 (20.5\%) and patient monitoring $130(16.0 \%)$ (Table 3). A total of 151 (18.6\%) errors were
Table 2 Frequency of Drug Classes Utilized by Admitted Patients in Nekemte Specialized Hospital

\begin{tabular}{|l|c|c|}
\hline Drug Classes & Frequency & Percent (\%) \\
\hline Antimicrobials & 374 & 22.2 \\
Analgesics & 260 & 15.4 \\
Electrolytes and fluids & 197 & 11.7 \\
Steroids & 75 & 4.5 \\
Cardiovascular drugs & 205 & 12.2 \\
Bronchodilators & 45 & 2.7 \\
Gastrointestinal drugs & 214 & 12.7 \\
Diuretics & 127 & 7.5 \\
Antihistamines & 99 & 5.8 \\
Anti-tuberculosis drugs & 37 & 2.2 \\
Others & 52 & 3.1 \\
\hline
\end{tabular}

intercepted before reaching the patient. From the errors that were reported $72(27.4 \%)$ were intercepted during physician order, 35 (36.1\%) were intercepted during transcription and 44 (38.3\%) were intercepted during dispensing before reaching the patient.

The severity of medication errors was reported using the NCC MERP. Accordingly, 33 (4.0\%) were classified as category A, $151(18.6 \%)$ were classified as category B, $599(73.7 \%)$ were classified as category $\mathrm{C}$ and $30(3.7 \%)$ were classified as category D (Table 4).

The most common cause of MEs was lack of knowledge of appropriate dosing/dosing guidelines, 183 (22.5\%) followed by lack of knowledge of indications for medication use, 160 (19.7\%), lab values/clinical information not available/noted, 103 (12.7) and concomitant medication(s) not available/noted, 88 (10.8\%) (Table 5).

Variables with $p$-value $<0.25$ in bivariable logistic regression analysis (age, hospital stay, number of medications taken, and presence of comorbidity) were entered into multiple logistic regression model to identify independent predictors of MEs. In the multivariable analysis, age $\geq 65$ years (AOR: 2.54, 95\%CI: 1.12-5.75, $p=0.025$ ), hospital stay $\geq 7$ days (AOR: $2.16,95 \% \mathrm{CI}$ : 1.17-3.98, $p=0.014$ ), number of medications taken (AOR: $1.75,95 \% \mathrm{CI}: 1.13-2.73, p=0.013$ ) and presence of comorbidity (AOR: 1.57, 95\%CI: 1.01-2.46, $p=0.049$ ) had shown statistical significance in predicting medication errors (Table 6).

\section{Discussion}

The present study followed 351 patients who fulfilled inclusion criteria prospectively for three months. Among the study participants, a total of 813 medication errors were recorded, 
Table 3 Type of Medication Errors and Stage of Errors Among Hospitalized Adults in Nekemte Specialized Hospital (MEs=8I3)

\begin{tabular}{|c|c|c|c|}
\hline \multicolumn{2}{|l|}{ Variables } & \multirow{2}{*}{$\begin{array}{c}\text { Frequency } \\
213\end{array}$} & \multirow{2}{*}{$\begin{array}{c}\begin{array}{c}\text { Percent } \\
\text { (\%) }\end{array} \\
26.2\end{array}$} \\
\hline Type of medication & Wrong drug & & \\
\hline \multirow[t]{10}{*}{ error } & Wrong dose & 183 & 22.5 \\
\hline & Wrong patient & 57 & 7.0 \\
\hline & Wrong & 81 & 10.0 \\
\hline & frequency & & \\
\hline & Wrong route & 45 & 5.5 \\
\hline & Wrong time & 47 & 5.8 \\
\hline & Omission & 12 & 1.5 \\
\hline & $\begin{array}{l}\text { Compliance } \\
\text { error }\end{array}$ & $4 I$ & 5.0 \\
\hline & $\begin{array}{l}\text { Monitoring } \\
\text { error }\end{array}$ & 130 & 16.0 \\
\hline & Other MEs ${ }^{\mathrm{a}}$ & 4 & 0.5 \\
\hline \multirow[t]{6}{*}{ Stage of error } & $\begin{array}{l}\text { Physician } \\
\text { ordering }\end{array}$ & 263 & 32.4 \\
\hline & Transcribing & 97 & 11.9 \\
\hline & $\begin{array}{l}\text { Nurse } \\
\text { administering }\end{array}$ & 167 & 20.5 \\
\hline & $\begin{array}{l}\text { Pharmacy } \\
\text { dispensing }\end{array}$ & 115 & 14.2 \\
\hline & $\begin{array}{l}\text { Patient } \\
\text { monitoring }\end{array}$ & 130 & 16.0 \\
\hline & Other ${ }^{\mathrm{b}}$ & 41 & 5.0 \\
\hline
\end{tabular}

Notes: ${ }^{a}$ Medication errors that do not fall into one of above categories; bedication errors that happen due to patient non-compliance.

at least one ME had been reported in $50.7 \%$ of patients and $37.3 \%$ of patients had three or more errors. The high incidence of medication error in this study was due to the poor practice of clinical pharmacy service in the center. During the study we have observed that the clinical pharmacist do not regularly attend the rounds and although there are physicians with specialty, it was the general practitioners that mostly follow the patient and write prescriptions. We believe that these conditions might have increased the rate of medication errors.
This study revealed elderly patients were at increased risk of medication error. Patients aged $\geq 65$ years experienced medication error three times more than those aged less than 65 years (AOR: 2.54, 95\% CI: 1.12-5.75, $p=0.025$ ). This is in line with studies from Japan, ${ }^{19}$ Britain, ${ }^{20}$ USA $^{21}$ Saudi Arabia, ${ }^{22}$ Pakistan $^{23}$ and Jordan ${ }^{24}$ in which older age was an independent predictor for medication error.

Hospital stay was an independent predictor of medication error in the present study. Patients who stayed seven days or beyond in hospital encountered medication errors more than two times than those who stayed for less than four days (AOR: 2.16, 95\%CI: $1.17-3.98, p=0.014$ ). This finding is consistent with the findings reported from Alem Ketema Enat Hospital of Ethiopia, ${ }^{25}$ USA, ${ }^{26}$ Egypt. ${ }^{27,28}$ This is because as the patient hospital stay is prolonged, the patient was exposed to multiple drug-related therapies, which necessitates passing through all medication use process like prescription, dispensing, transcription, and administration that may increase the occurrences of MEs. It can be further justified that hospital stay is relatively longer in severe medical cases, which again results in very close follow-up, which might have increased the number of medications, which sounds scientific following polypharmacy being an independent predictor of MEs in the current study.

Polypharmacy was also significantly associated with MEs in the present study. Patients taking $\geq 5$ drugs experienced nearly two times more medication errors than those who took $\leq 4$ medications (AOR: 1.75, 95\%CI: 1.13-2.73, $p=0.013$ ). This finding is in line with different studies reported across the globe, including Alem Ketema Enat Hospital of Ethiopia, ${ }^{25}$ Pakistan, ${ }^{23}$ Saudi Arabia, ${ }^{22}$ Japan, ${ }^{19}$ China, ${ }^{29}$ Brazil $^{30}{ }^{30} \mathrm{USA}^{31}$ and Sweden ${ }^{32}$ supporting the general fact that polypharmacy might result in adverse drug events.

The other factor with affects attributed to medication error was the presence of comorbid cases, in addition to the medical case resulting in admission. In the present

Table 4 Severity Categories of Medication Errors Among Hospitalized Adults in Nekemte Specialized Hospital ( $n=8 \mid 3)$

\begin{tabular}{|l|c|c|}
\hline Severity Categories of MEs & Frequency & Percent (\%) \\
\hline (A) Circumstances or events that have the capacity to cause error & 4.0 & 33 \\
(B) An error occurred but the error did not reach the patient & 18.6 & 59 \\
(C) An error occurred that reached the patient but did not cause patient harm & 73.7 & 30 \\
(D) An error occurred that reached the patient and required monitoring or intervention to confirm that it resulted & 3.7 & 30 \\
in no harm to the patient and/or required intervention to preclude harm & 3 \\
\hline
\end{tabular}


Table 5 Possible Causes of MEs Among Hospitalized Adults in Nekemte Specialized Hospital (MEs=8|3)

\begin{tabular}{|l|c|c|}
\hline Possible Causes of MEs & Frequency & Percent (\%) \\
\hline Allergy information not available/noted & 42 & 5.2 \\
Concomitant medication(s) not available/noted & 88 & 10.8 \\
Concomitant condition(s) not available/noted & 74 & 9.1 \\
Lab values/clinical information not available/noted & 103 & 12.7 \\
Lack of knowledge of indications for medication use & 160 & 19.7 \\
Lack of knowledge of appropriate dosing/dosing guidelines & 183 & 22.5 \\
Lack of knowledge of appropriate routes for administration & 45 & 5.5 \\
Lack of knowledge of drug compatibility & 15 & 1.9 \\
Use of abbreviations in medication ordering & 14 & 1.7 \\
Incomplete medication order processed & 19 & 2.3 \\
Patient identification not checked & 57 & 7.0 \\
Illegible physician handwriting & 13 & 1.6 \\
\hline
\end{tabular}

Table 6 Odds Ratio of Factors Associated with ME Among Hospitalized Adults in Nekemte Specialized Hospital ( $n=35 \mathrm{I}$ )

\begin{tabular}{|c|c|c|c|c|}
\hline \multicolumn{2}{|l|}{ Variables } & \multicolumn{2}{|c|}{ Medication Error } & \multirow[t]{2}{*}{ AOR (95\%Cl) p-value } \\
\hline & & No $(n=\mid 73)$ & Yes $(n=\mid 78)$ & \\
\hline \multirow[t]{2}{*}{ Sex } & Female & 77 & 77 & - \\
\hline & Male & 96 & 101 & - \\
\hline \multirow[t]{3}{*}{ Age } & $18-34$ & 82 & 58 & 1.00 \\
\hline & $35-64$ & 80 & 98 & $1.66(1.05-2.64) p=0.031$ \\
\hline & $\geq 65$ & 11 & 22 & $2.54(1.12-5.75) p=0.025$ \\
\hline \multirow[t]{3}{*}{ Hospital stay } & $1-3$ & 65 & 40 & 1.00 \\
\hline & $4-6$ & 75 & 89 & $1.74(1.04-2.91) p=0.035$ \\
\hline & $\geq 7$ & 33 & 49 & $2.16(1.17-3.98) p=0.014$ \\
\hline \multirow[t]{2}{*}{ Number of medication taken } & $\leq 4$ & 92 & 66 & 1.00 \\
\hline & $\geq 5$ & 81 & 112 & $1.75(1.13-2.73) p=0.013$ \\
\hline \multirow[t]{2}{*}{ Presence of comorbidity } & No & 80 & 59 & 1.00 \\
\hline & Yes & 93 & 119 & $1.57(1.01-2.46) p=0.049$ \\
\hline
\end{tabular}

Abbreviation: AOR, adjusted odds ratio.

study, patients with comorbidity experienced two times more medication errors than patients without comorbidity (AOR: 1.57, 95\%CI: $1.01-2.46, p=0.049$ ). This is consistent with the findings from studies conducted in Alem Ketema Enat Hospital of Ethiopia, ${ }^{25}$ Pakistan, ${ }^{23}$ USA $^{17}$ clearly showing that there was a statistically significant association between the number of disease conditions and MEs. This might be due to the presence of comorbidity means patients take more medication, which increases the chance of occurrence of the error.

The most common types of medication errors in the present study were the wrong drug followed by wrong dose, and monitoring error. This was in line with studies conducted in Pakistan, ${ }^{23}$ where invalid indication was the leading medication error reported, and Alem Ketema Enat Hospital of
Ethiopia $^{25}$ reporting unnecessary drug therapy as the commonest medication error. But this finding was not consistent with the study from Denmark, ${ }^{33}$ which reported lack of drug form as the commonest medication error and the difference might be because of the fact that the study in Denmark included health-care professionals as the study subjects, which might have resulted in underreporting of professionals related errors like ordering and administering errors.

Our finding was also not in line with a finding from a study conducted at Jimma University Specialized Hospital of Ethiopia, ${ }^{34}$ which reported wrong time followed by omission due to unavailability of the drug as the most common medication error in that study. This difference arose following the study at JUSH focusing on Medication administration only. 
Medication errors occurred at different stages of patient care in the present study. Nearly one-third $(32.4 \%)$ of the total medication errors were due to physicians ordering followed by nurses administering, pharmacists dispensing, and patient monitoring stages. Most of the medication errors committed were due to lack of knowledge of appropriate dosing guidelines and lack of knowledge of indications of medication use, unavailability of laboratory values or clinical information and unavailable medication or unrevealed medical conditions. This was consistent with the study conducted in Alem Ketema Enat Hospital of Ethiopia, ${ }^{25}$ Brazil $^{35}$ Uganda $^{36}$ in which physician ordering is the most common stage leading to medication error. To overcome these causes of medication errors the clinical pharmacy service has to be given effectively and prescribing physicians have to get training on the appropriate prescribing practice. Furthermore we recommend pharmacist-led medication reconciliation, pharmacist partnership, prescriber education, and computerized physician order entry (CPOE) as strategy to improve drug safety.

\section{Limitations}

The awareness of the study by the health-care professionals working in the study wards could have affected both the occurrence and detection of errors. This study did not assesse prescriber level factors like prescriber physician experience. Furthermore, as we were ethically obliged to take corrective action when we identified serious practice problems, the incidence of errors could have been reduced as the study progressed.

\section{Conclusions}

Medication error was prevalent and was detected in most of the patients with 48.3 errors per 100 orders and 433.4 errors per 1000 patient-days. Multivariable logistic regression analysis shows age, length of hospital stay, the number of medications the patient took, and comorbidity were independent predictors of medication errors. Hence, every error should be assessed to determine the contributing factors in the medication use process and design the appropriate strategies to prevent the occurrence of medication errors. In this way, the health-care providers and those who manage health systems can understand and learn from errors to improve patient safety.

\section{Abbreviations}

ADE, adverse drug event; ADR, adverse drug reaction; JUSH, Jimma University Specialized Hospital; ME, medication error; NCC MERP, National Coordinating Council For Medication Error Reduction And Prevention; NSH, Nekemte Specialized Hospital; USA, United States of America.

\section{Data Sharing Statement}

The datasets are available from the corresponding author and will be available upon request. The questionnaire used to ask information from the patients is available as Supplementary Material.

\section{Acknowledgments}

We are grateful to the department of pharmacy, Wollega University for their unreserved cooperation in making this study to be a fruitful work. We are also thankful for the health-care professionals of Nekemte Specialized Hospital for their cooperation in collecting the data and the patients who willingly participated in this study.

\section{Author Contributions}

All authors contributed to data analysis, drafting or revising the article, gave final approval of the version to be published, agreed to the submitted journal, and agree to be accountable for all aspects of the work.

\section{Funding}

There was no funding for this work.

\section{Disclosure}

The authors report no conflicts of interest for this work.

\section{References}

1. Malone PM, Kier KL, Stanovich JE. Drug Information, a Guide for Pharmacists. 3rd ed. New York: McGraw-Hill; 2006.

2. Adverse Drug Events, Adverse Drug Reactions and Medication Errors: Frequently Asked Questions. Veterans affairs center for medication safety and veterans health administration pharmacy benefits management strategic healthcare group and the medical advisory panel; 2006.

3. McBride-Henry K, Foureur M. Medication administration errors: understanding the issues. Aust J Adv Nurs. 2006;23(3):33-41.

4. Bates DW, Cullen DJ, Laird N, et al. Incidence of adverse drug events and potential adverse drug events: implications for prevention. JAMA. 1995;274(1):29-34. doi:10.1001/jama.1995.03530010043033

5. Leape LL, Bates DW, Cullen DJ, et al. Systems analysis of adverse drug events. ADE Prevention Study Group. JAMA. 1995;274 (1):35-43. doi:10.1001/jama.1995.03530010049034

6. Kaushal R, Bates DW, Landrigan C, et al. Medication errors and adverse drug events in pediatric inpatients. $J$ Am Med Assoc. 2001;285(16):2114-2120. doi:10.1001/jama.285.16.2114 
7. Bates DW, Boyle DL, Vliet MBV, Schneider J, Leape L. Relationship between medication errors and adverse drug events. $J$ Gen Intern Med. 1995;10(4):199-205. doi:10.1007/BF02600255

8. Carleton B, Lesko A, Milton J, Poole RL. Active surveillance systems for pediatric adverse drug reactions: an idea whose time has come. Curr Ther Res. 2001;62(10):738-742. doi:10.1016/S0011393X(01)80080-1

9. Creation of a better medication safety culture in Europe: building up safe medication practices. Council of Europe Expert Group on Safe Medication Practices; 2006.

10. Fialová D, Onder G. Medication errors in elderly people: contributing factors and future perspectives. Br J Clin Pharmacol. 2009;67 (6):641-645. doi:10.1111/j.1365-2125.2009.03419.x

11. Atkin PA, Veitch PC, Veitch EM, Ogle SJ. The epidemiology of serious adverse drug reactions among the elderly. Drugs Aging. 1999;14:141-152. doi:10.2165/00002512-199914020-00005

12. Food, Medicine and Health Care Administration and Control Authority of Ethiopia. Standard treatment guidelines for general hospitals. 3rd Edition; 2014.

13. Dipiro JT, Talbert RL, Yee G, et al. Pharmacotherapy, a Pathophysiologic Approach. 11th ed. McGraw-Hill Education; 2020.

14. California Healthcare Foundation. Addressing medication errors in hospitals: ten tools. Protocare Sciences; 2001:8-13. Available from: https://www.chcf.org/wp-content/uploads/2017/12/PDFaddressingmederrorstentools.pdf. Accessed August 18, 2020.

15. Pediatric Trigger Toolkit. Measuring adverse drug events in the children's hospital. Child Health Corporation of America; 2007.

16. Rozich JD, Haraden CR, Resar RK. Adverse drug event trigger tool: a practical methodology for measuring medication related harm. Qual Saf Health Care. 2003;12:194-200. doi:10.1136/qhc.12.3.194

17. American Society of Hospital Pharmacists. ASHP guidelines on preventing medication errors in hospitals. Am J Hosp Pharm. 1993;50:305-314.

18. Barker KN, Flynn EA, Pepper GA, Bates DW, Mikeal RL. Medication errors observed in 36 health care facilities. Arch Intern Med. 2002;162(16):1897-1903. doi:10.1001/archinte.162.16.1897

19. Morimoto T, Sakuma M, Matsui K, et al. Incidence of adverse drug events and medication errors in Japan: the JADE study. J Gen Intern Med. 2010;26(2):148-153. doi:10.1007/s11606-010-1518-3

20. Vincent C, Neale G, Woloshynowych M. Adverse events in British hospitals: preliminary retrospective record review. BMJ. 2001;322 (7285):517-519. doi:10.1136/bmj.322.7285.517

21. Hug BL, Witkowski DJ, Sox CM, et al. Adverse drug event rates in six community hospitals and the potential impact of computerized physician order entry for prevention. J Gen Intern Med. 2009;25 (1):31-38. doi:10.1007/s11606-009-1141-3

22. Assiri GA, Alkhenizan AHM, Al-Khani SM. Investigating the epidemiology of medication errors in adults in community care settings. Saudi Med J. 2019;40(2):158-167. doi:10.15537/smj.2019.2.23933

23. Rasool MF, Rehman A, Imran I, et al. Risk factors associated with medication errors among patients suffering from chronic disorders. Front Public Health. 2020;8:531038. doi:10.3389/fpubh.2020.531038
24. Salameh L, Farha RA, Basheti I. Identification of medication discrepancies during hospital admission in Jordan: prevalence and risk factors. Saudi Pharm J. 2018;26(1):125-132. doi:10.1016/j. jsps.2017.10.002

25. Kebede B, Kefale Y. Medication error patients admitted to medical ward in primary hospital, Ethiopia: prospective observational study. J Pharma Care Health Sys. 2019;6(205):2376-0419.

26. McCarthy BC, Tuiskula KA, Driscoll TP, Davis AM. Medication errors resulting in harm: using chargemaster data to determine association with cost of hospitalization and length of stay. Am J Health Syst Pharm. 2017;74(23):S102-S107. doi:10.2146/ajhp160848

27. Ali MAS, Lobos CM, Abdelmegid MAF, El-Sayed AM. The frequency and nature of medication errors in hospitalized patients with acute coronary syndrome. Int J Clin Pharm. 2017;39(3):542-550. doi:10.1007/s11096-017-0457-z

28. Bazan NS, Darweesh EA, El-Sherif A. Medication errors in Egyptian critically ill patients with renal insufficiency: an assessment of the need for optimizing clinical pharmacy service. Int J Pharm Sci \& Res. 2018;9(8):3523-3529.

29. Holdsworth MT, Fichtl RE, Behta M, et al. Incidence and impact of adverse drug events in pediatric inpatients. Arch Pediatr Adolesc Med. 2003;157:60-65. doi:10.1001/archpedi.157.1.60

30. Silva DCB, Araujo OR, Arduini RG, Alonso CFR, Shibata ARO, Troster EJ. Adverse drug events in a pediatric intensive care unit: a prospective cohort. BMJ Open. 2013;3:1868-1875. doi:10.1136/ bmjopen-2012-001868

31. Picone DM, Titler MG, Dochterman J, et al. Predictors of medication errors among elderly hospitalized patients. Am J Med Qual. 2008;23 (2):115-127. doi:10.1177/1062860607313143

32. Hellstrom LM, Bondesson A, Hoglund P, Tommy E. Errors in medication history at hospital admission: prevalence and predicting factors. BMC Clin Pharmacol. 2012;12:9. doi:10.1186/1472-6904$12-9$

33. Lisby M, Nielsen LP, Mainz J. Errors in the medication process: frequency, type, and potential. Int J Qual Health Care. 2005;17 (1):15-22. doi:10.1093/intqhe/mzi015

34. Agalu A, Ayele Y, Bedada W, Woldie M. Medication administration errors in an intensive care unit in Ethiopia. Int Arch Med. 2012;5 (1):15. doi:10.1186/1755-7682-5-15

35. Dalmolin GR, Rotta ET, Goldim JR. Medication errors: classification of seriousness, type, and of medications involved in the reports from a University Teaching Hospital. Braz J Pharm Sci. 2013;49 (4):793-802. doi:10.1590/S1984-82502013000400019

36. Dorothy A, Yadesa TM, Atukunda E. Prevalence of medication errors and the associated factors: a prospective observational study among cancer patients at Mbarara regional referral hospital. Cancer Manag Res. 2021;13:3739-3748. doi:10.2147/CMAR.S307001
Drug, Healthcare and Patient Safety

\section{Publish your work in this journal}

Drug, Healthcare and Patient Safety is an international, peer-reviewed open-access journal exploring patient safety issues in the healthcare continuum from diagnostic and screening interventions through to treatment, drug therapy and surgery. The journal is characterized by the rapid reporting of reviews, original research, clinical, epidemiological and post-marketing surveillance studies, risk management, health literacy and educational programs across all areas of healthcare delivery. The manuscript management system is completely online and includes a very quick and fair peer-review system. Visit http://www.dovepress.com/testimonials.php to read real quotes from published authors. 